\title{
Reorganization of mental health services: from institutional to community-based models of care
}

B. Saraceno, ${ }^{7}$ R. Gater, ${ }^{2}$ A. Rahman, ${ }^{3}$ K. Saeed, ${ }^{4}$ J. Eaton, ${ }^{5}$ G. Ivbijaro, ${ }^{6}$ M. Kidd, ${ }^{7}$ C. Dowrick, ${ }^{8}$ C. Servili, ${ }^{9}$ M. K. Funk ${ }^{10}$ and C. Underhill ${ }^{11}$

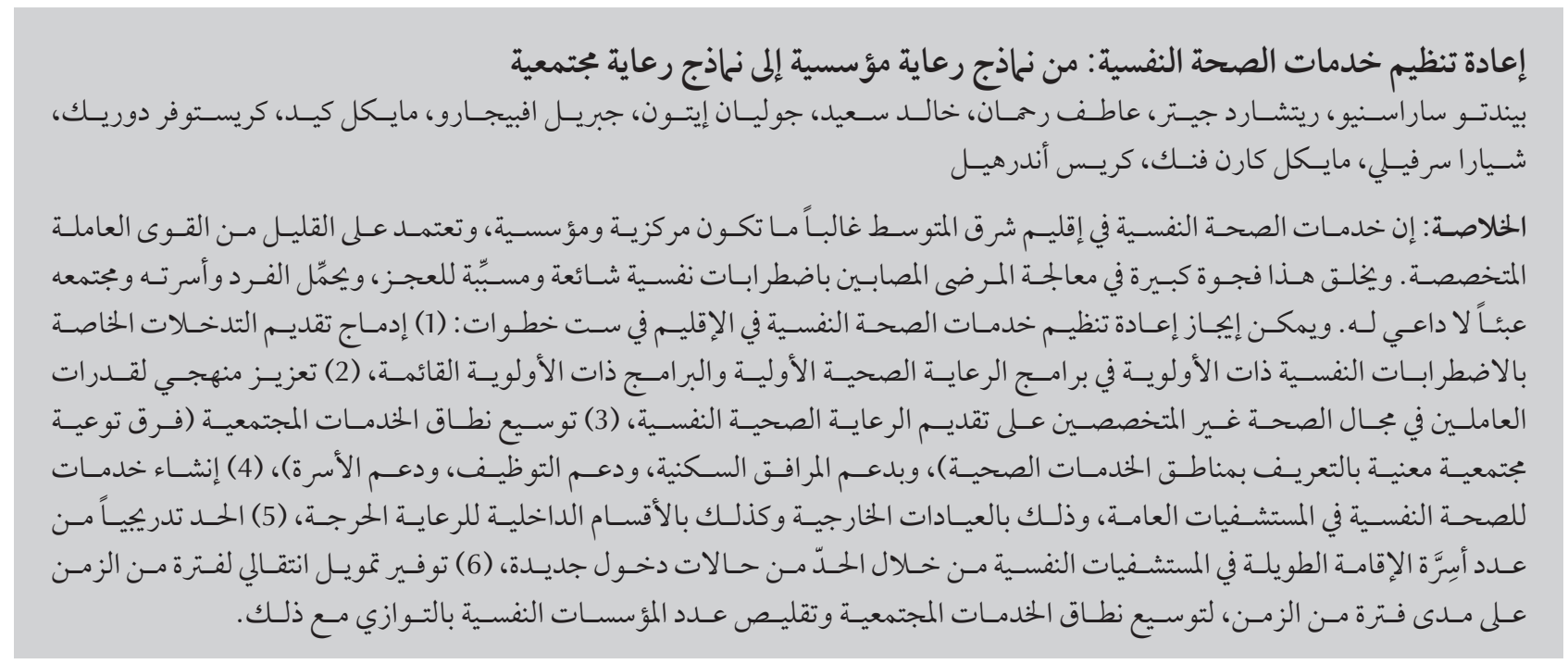

ABSTRACT Mental health services in the Eastern Mediterranean Region are predominantly centralized and institutionalized, relying on scarce specialist manpower. This creates a major treatment gap for patients with common and disabling mental disorders and places an unnecessary burden on the individual, their family and society. Six steps for reorganization of mental health services in the Region can be outlined: (1) integrate delivery of interventions for priority mental disorders into primary health care and existing priority programmes; (2) systematically strengthen the capacity of non-specialized health personnel for providing mental health care; (3) scale up community-based services (community outreach teams for defined catchment, supported residential facilities, supported employment and family support); (4) establish mental health services in general hospitals for outpatient and acute inpatient care; (5) progressively reduce the number of long-stay beds in mental hospitals through restricting new admissions; and (6) provide transitional/bridge funding over a period of time to scale up community-based services and downsize mental institutions in parallel.

Réorganisation des services de santé mentale : des modèles de soins institutionnels aux modèles communautaires

RÉSUMÉ Les services de santé mentale dans la Région de la Méditerranée orientale sont essentiellement centralisés et institutionnalisés. Ils reposent sur un personnel spécialisé qui est rare. Cette situation crée un large fossé thérapeutique pour les patients atteints de troubles mentaux courants et handicapants, et fait porter une charge inutile pour l'individu, sa famille et la société. Six étapes pour la réorganisation des services de santé mentale dans la Région peuvent être présentées de la manière suivante : 1) intégrer l'offre des interventions pour les troubles de santé mentale prioritaires dans les programmes de soins de santé primaires et les programmes prioritaires existants ; 2) renforcer systématiquement les capacités du personnel de santé non spécialisé à fournir des soins de santé mentale ; 3) intensifier les services communautaires (équipes communautaires de proximité pour une zone de desserte définie, établissements résidentiels bénéficiant d'assistance aide à l'emploi et soutien apporté à la famille) ; 4) établir des services de soins de santé mentale dans des hôpitaux généraux pour les soins externes et les soins aigus chez le patient hospitalisé ; 5) réduire progressivement le nombre de lits de long séjour dans les hôpitaux de soins de santé mentale en diminuant le nombre des nouvelles admissions ; 6) fournir un financement de transition/provisoire pendant une certaine durée pour intensifier les services communautaires et parallèlement réduire la taille des institutions de santé mentale.

${ }^{7}$ Faculdade de Ciências Médicas, UniversidadeNova de Lisboa, Lisbon, Portugal. ${ }^{2}$ Institute of Brain, Behaviour and Mental Health, University of Manchester, and Lancashire Care NHS Foundation Trust, United Kingdom (Correspondence to B. Saraceno: benedetto.saraceno@gmail.com). (Continued on page 405) 


\section{The case for reorganizing mental health services: the optimal mix of services}

Mental disorders are common and disabling. About 1 person in every 10 worldwide is suffering from a mental disorder, and 1 in 4 families has a family member with a mental disorder (1). Rates of mental disorder are even higher in countries affected by complex emergencies. The vast majority of people with a mental disorder do not receive treatment. The treatment gap, i.e. the proportion of people who require care but do not receive treatment, has been estimated to be more than $90 \%$ in the Eastern Mediterranean Region (EMR). The limited resources that are available for mental health care in these countries are often deployed inefficiently in maintaining large psychiatric hospitals that are inaccessible to the majority of the population, may result in poor clinical and social outcomes and have even been associated with human rights violations.

Yet effective pharmacological and psychosocial treatments are available for depression, schizophrenia, epilepsy, alcohol and substance abuse and these treatments can be successfully applied in integrated, community-based mental health services in low-income countries $(1,2)$. Hence there is a compelling case for reorganizing services into a decentralized, integrated community-based model of delivery for mental health care.

The major demographic changes which are taking place in almost all the countries of the EMR should be carefully considered when planning the scaling-up and reorganization of mental health services. The child and adolescent population is growing fast and this phenomenon should drive public health policy-makers when they plan mental health care and services, to avoid the risk of focusing exclusively on services for the adult population. In addition, the massive migration from rural to urban areas which is ongoing should also significantly influence not only the location of services but also the ability of services to address the new and specific needs of populations who are recently urbanized and often live in critically underserved environments.

\section{Achieving reorganization: catalysts for change}

Despite previous attempts to improve mental health services, decentralization and integration in the EMR is patchy, services are inadequately funded and resources remain centralized in mental hospitals (Figure 1). Successful initiatives in the Region have identified and taken advantage of opportunities to catalyse change:

- Crisis can be a catalyst for change. Emergency situations provide the opportunity for review and adoption of new approaches, as exemplified by developments in Afghanistan, Iraq, Jordan and Somalia.

- The community itself can provide crucial impetus and direction for the reorganization of services. This invaluable resource needs to be facilitated by fostering the development of family/carer and user groups. Box 1 is a case study from Morocco illustrating the how family associations can play a role in mental health care in the community.

- External donor pressure can be the driver to ensure that models of service delivery are effective and efficient and

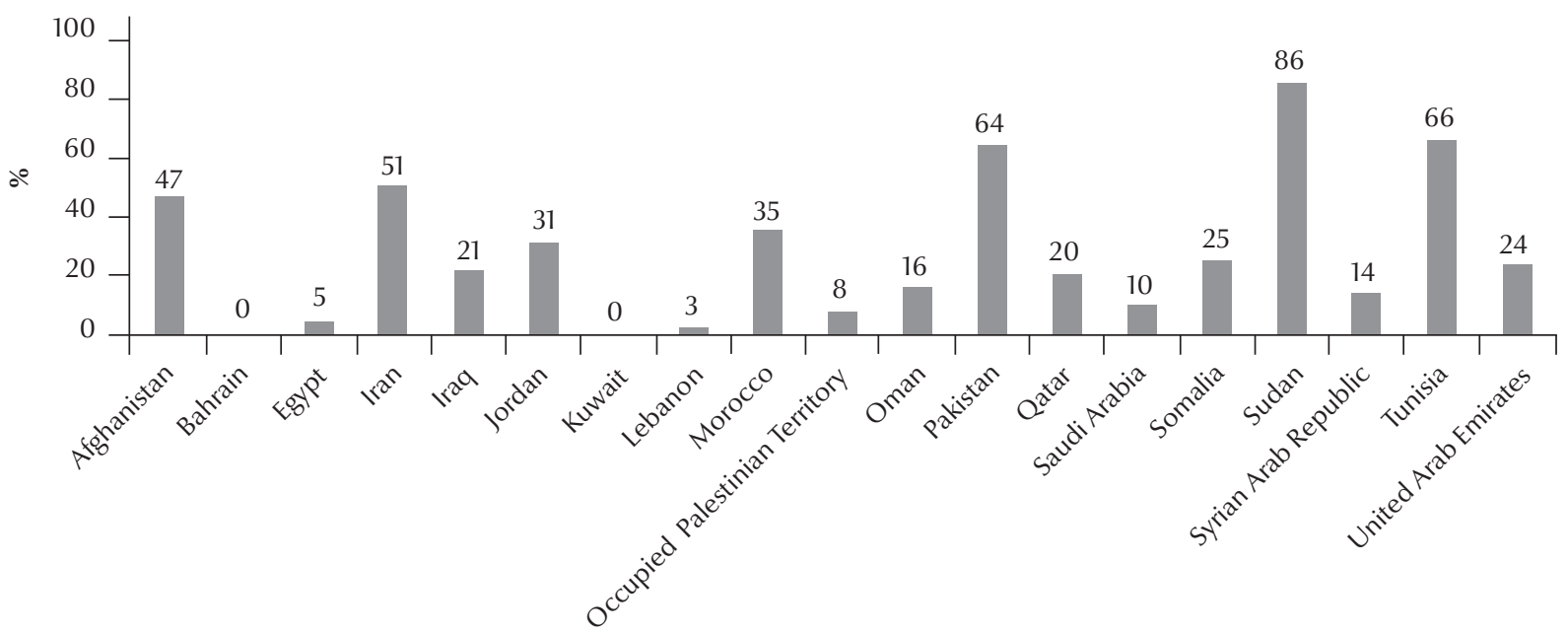

Figure 1 Percentage of all psychiatric beds that are in general hospital and community residences in countries of the Eastern Mediterranean Region 


\section{Box 1 Case study: role of family associations in improving quality of mental health care in Morocco}

In February 2007, a group of family members in Morocco created the AMALI association ("my hope" in Arabic) in order to improve the quality of life of mental patients and to advocate to the community and decision-makers for better care for mental health problems. AMALI aims to: fight taboos and stigmatization, isolation of patients and families, discrimination and social rejection of patients; advocate to decision-makers for improving the quality of hospital infrastructure, for better access to care and for availability of treatment for the most socially vulnerable populations; contribute to and promote legal texts for the protection of human rights of patients; promote the development of institutions for social rehabilitation of mental patients; receive families, listen to their problems and inform and train them with psychoeducation programmes, e.g. the Profamille programme; and participate in national and international congresses as well as seminars on mental health.

The activities of AMALI have helped the Minister of Health to declare mental health as the second highest priority of the Ministry and have contributed to the report of the Moroccan national council of human rights (Comité National des Droits Humains) describing the shortcomings of psychiatric institutions and the solutions to adopt. AMALI association helped also in creating the first association of psychiatry service users in Morocco (Association Marocaine des Usagers de la Psychiatrie).

that they meet standards of quality and human rights.

- Adoption of mental health policy and legislation incorporating internationally accepted human rights conventions can drive service reorganization since it requires a service model that can successfully meet the requirements of the legal framework. The right to community-based services is expressly recognized in Article 19 of the United Nations Convention on the Rights of Persons with Disabilities.

- Momentum generated by the development of delivery platforms for priority programmes, e.g. HIV/AIDS, maternal and child health and noncommunicable diseases, can sometimes provide opportunities for reorganizing the service delivery model for mental health.

\section{What needs to be done?}

The World Health Organization (WHO) has developed the Service Organization Pyramid Model for an Optimal Mix of Services for Mental Health (Figure 2). This model incorporates the recovery paradigm, which proposes that people with mental disorders are central to their own recovery and can manage their mental health problems themselves, supported by family, friends and community institutions. At successively higher levels of the pyramid the mental health needs of the individual require more intensive professional assistance with commensurate higher costs of care.

\section{Integrate mental health care into primary health care}

Although all countries in the Region have made some progress towards integrating mental health services into the primary health care system, there is considerable variation in the extent of integration (Figure 3). The case study in Box 2 looks at how the Islamic Republic of Iran has successfully integrated mental health services into all levels of care nationwide. Integration of mental health into primary care improves identification and treatment rates for priority mental disorders and promotes access

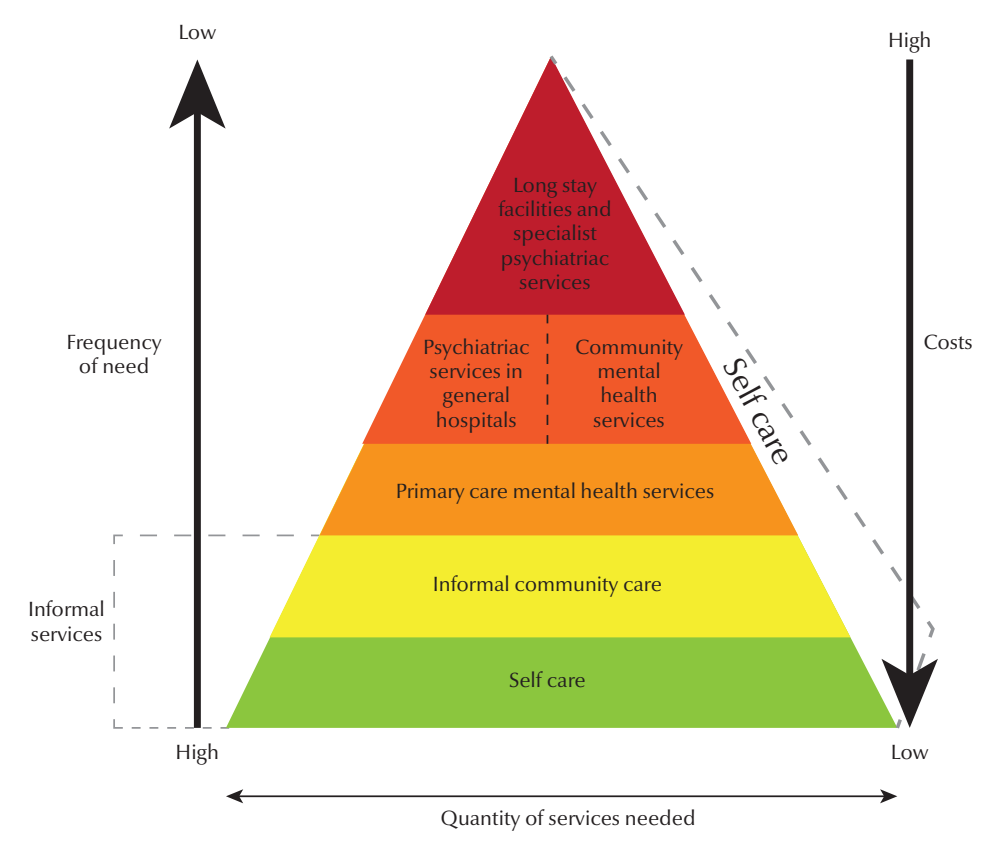

Figure 2 WHO Service Organization Pyramid for an Optimal Mix of Services for Mental Health (3) 
and holistic care for comorbid physical and mental health problems (3). Even in countries where primary health care services are weak, this can be achieved if primary care workers are provided with training followed by sufficient support and supervision by secondary-level services. The WHO Mental Health Gap Action Programme (mhGAP) provides resources to support the provision of front-line services for a range of priority conditions to be delivered through primary health care and other non-specialist settings.

\section{Community-based services for mental health care delivery}

Community-based services, such as mental health outpatient facilities and daytreatment facilities are underdeveloped in the EMR compared with the rest of the world, and the provision of community residential facilities is much lower than in European countries. There is a widespread clinical consensus that people receiving community-based mental health care have better health and mental health outcomes and better quality of life than those treated in institutional psychiatric settings (5). Community services can be scaledup in resource-poor settings by using non-mental-health professionals (6-8). Box 3 shows a case study from Palestine. Adopting a whole community approach can compensate for health service manpower shortages and provide avenues to incorporate income generation and group management interventions (9).

\section{Psychiatric units in general hospitals}

Across the EMR the availability of psychiatric beds in general hospitals is about one-third of that found in the rest of the world. Two-thirds of psychiatric beds in the EMR are still located in mental hospitals, the remainder being almost equally divided between general hospitals (18\%) and community residences (16\%). There is a very wide variation between EMR countries in the extent to which psychiatric beds are located in community settings (Figure 1).

General hospital settings provide an accessible and acceptable location for 24-hour medical care and supervision of people with acute acerbations of mental disorders, in the same way that these facilities manage acute exacerbations of physical health disorders. Although there is a consensus that acute inpatient services are necessary both to diagnose and to treat patients, the number of beds needed is contingent on which other services exist locally and on local social, economic and cultural characteristics.

\section{Scale-back and refocus psychiatric hospitals}

Successful deinstitutionalization programmes involve investment in community-based services, development of human resources with an appropriate skill mix and parallel funding to manage the transition. The range and capacity of residential long-term care that will be needed in any particular area is dependent upon which other services are available or developed locally, and upon social and cultural factors, such as the amount of family care provided (10). When deinstitutionalization is carried out carefully for those who previously received long-term inpatient care, the outcomes are more favourable for most patients who are discharged into community care (11-13). Improvement of quality of care in psychiatric hospitals and processes of deinstitutionalization should be encouraged, developed and monitored (14). Existing psychiatric hospitals in the EMR can respond to this need by developing as tertiary centres of excellence. However, it should be noted that in some countries the total number of psychiatric beds in psychiatric and general hospitals is very low and in those cases the effort should be directed towards increasing mental health beds in general hospitals in spite of the well-known resistance to

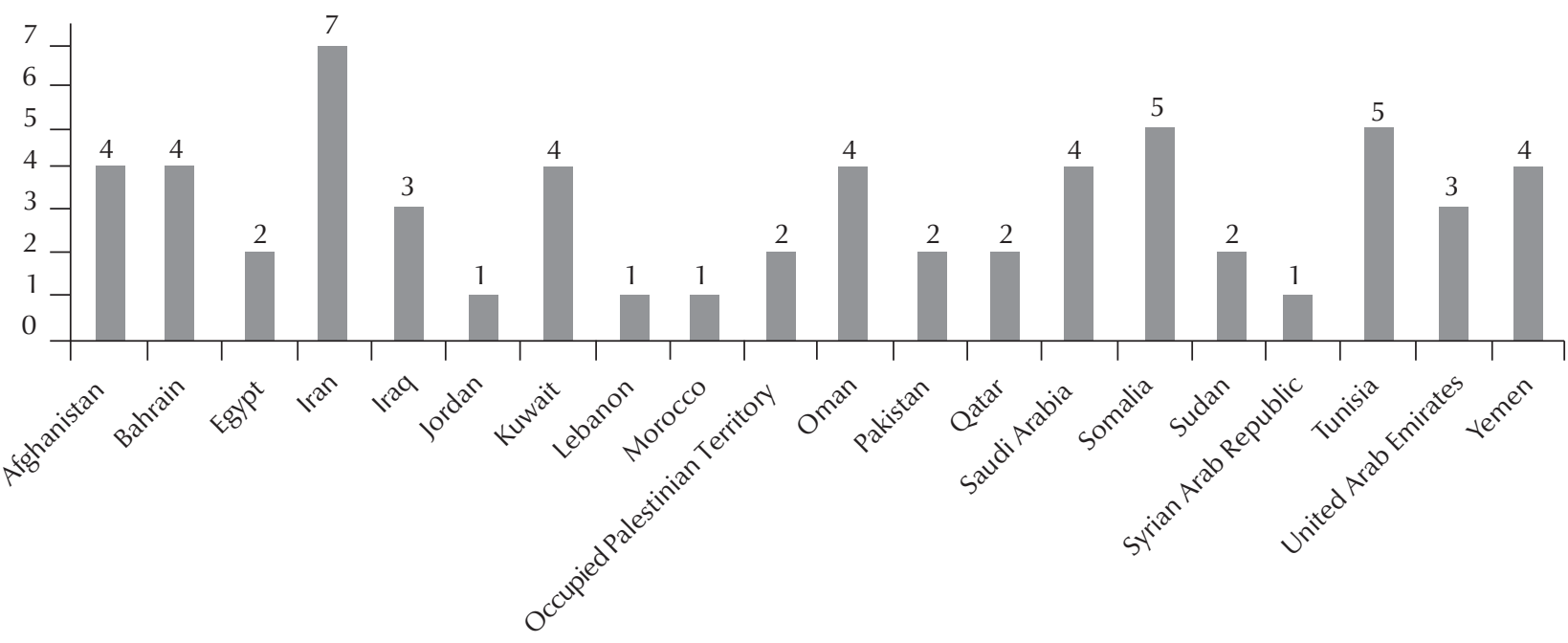

Figure 3 Progress towards integration of mental health into primary care in countries of the Eastern Mediterranean Region: crude sum of 7 primary health care indicators collected in the Mental health atlas 2011 (4) 


\section{Box 2 Case study: integration of mental health into primary health care in Islamic Republic of Iran}

A national mental health programme in the Islamic Republic of Iran was adopted by the Ministry of Health and Medical Education in 1988. Based on the evaluation of pilot projects, the Ministry decided to scale up the model of integrated primary and mental health care services to the whole country.

The scope of practice and clinical priorities are defined for the different levels of health care. At village level, the responsibilities of the behvarz (community health workers manning health houses in the community) was expanded to include mental health. In addition to training on mental health as part of their general curriculum, they attend refresher courses held by general practitioners, psychologists or psychiatrists at the provincial level. They are continually supervised by more senior health workers at the primary care centres.

The primary care centres are responsible for identifying and treating severe mental disorders, common mental disorders, epilepsy and mental retardation. General practitioners, who manage urban and rural primary health centres, receive a 1-2-week training session in mental health, as well as refresher training every 1-3 years. This training is provided by a provincial-level psychiatrist. The general practitioners in turn train the disease control technicians in their catchment area, focusing on diagnosis, management and referral of mental disorders.

The district health centres are responsible for the planning, management, implementation and supervision of activities within their health network of rural and urban health centres and village health houses. They in turn are supervised and supported by the provincial mental health units staffed by a psychiatrist and a psychologist, who are responsible for the technical, organizational and administrative management of the services at the periphery.

The deans of the medical universities in every province are responsible both for medical education and for health services in their catchment area, with full collaboration from the senior provincial health administration, especially the directors of the primary care network. This promotes continuity of care across different tiers of the system.

The Islamic Republic of Iran's strong ties between its medical education and health sectors facilitates the training of health workers throughout the country. As such, the medical universities provide strong scientific support for the programme. Nationwide training of general practitioners and behvarz using specially designed manuals and learning support tools has been completed on a province-by-province basis over the last 2 decades, and continues for new health workers and for those who need retraining and upgrading of their skills. A referral system for patients from health houses to specialized university facilities is in place.

Research on treatment pathways indicates that the expansion of mental health care into primary care has reduced assistance sought from traditional practitioners; first contact with a traditional health practitioner for a mental health problem has decreased from 40\% in 1990 to $14 \%$ in 1998 and 16\% in 2000. Integration of mental health in primary health care has also provided the foundation for expanding the scope of service to other areas. For example, a national suicide prevention programme is being implemented through training general practitioners in the treatment of depression (especially in regions where suicide rates are high), referral of suicidal patients, follow-up of people who have attempted suicide and control of potential social contagion. Nevertheless, challenges remain, such as the high mobility of general practitioners, particularly in more remote areas, and the fact that the behvarz who are essential to the programme's success in rural areas do not exist in urban settings where the private health sector is dominant and not well-regulated. Public-private partnerships are weak or nonexistent. Therefore, currently efforts are underway to develop community mental health centres with outreach services in the urban areas where $70 \%$ of the population is living.

this by professionals working in general hospitals. The WHO QualityRights Tool Kit is a useful resource to guide the process of examining the human rights situation in institutions and guiding collaborative reform (15). While reducing the numbers of patients residing in long-stay facilities will release resources to pay for the development of community-based mental health services, it needs to be stressed that parallel dual funding will still be required during the period of reorganization.

\section{Integrate mental health into priority health service delivery platforms}

An integrated approach to addressing mental health in the context of care for HIV, maternal and child health and noncommunicable diseases has been shown to be cost-effective and efficient (16-18). Maternal and child health programmes are population- and community-based and can provide a platform for equitable care, especially in rural and difficult-to-access communities $(19,20)$ and offer the chance to treat the "whole patient", which has beneficial effects not only for the individual but also for his/her family. Box 4 


\section{Box 3 Case study: developing community mental health services in Palestine}

In Palestine, the mental health resources of the Ministry of Health have historically been concentrated ian tertiary psychiatric facilities with minimal investment in community-based care. Other problems included outdated models of care (i.e. the biomedical treatment model), shortage of mental health professionals, lack of training for mental health and primary care workers and the large treatment gap for people who need mental health care but are not able to attain it due to lack of awareness, misconceptions, stigma and discrimination.

Since $2002 \mathrm{WHO}$, in collaboration with the Palestine Ministry of Health and other partners, has supported an ongoing process of mental health care reform throughout the West Bank and Gaza. Overall, the reform initiative seeks to: improve the accessibility to quality mental health services in all levels of care; develop a community-based care system for mental health; and improve health-care-seeking behaviour among patients in need of care.

Stigma towards mental health care among health workers remains a problem. Despite much effort, directors of general hospitals have so far refused to introduce psychiatric acute care beds. Without ongoing support from donors, the sustainability of the local Friends and Family Associations is a concern. While the merits of establishing such associations cannot be disputed, it is important to note that a high degree of organizational capacity-building and support may be needed for a sustained period of time. Mental health workers may not be best qualified to provide such support. It may be better to try to link these associations with well-established organizations.

The reform process has involved interventions at multiple levels and across all areas of West Bank and Gaza, with a potential impact on the entire population. The process of integration of mental health into primary health care was initially piloted in one district (including 7 clinics) in Gaza. After a successful 6-month pilot period, the programme was expanded to a second district. The current implementation plan involves moving to a new district at 6 -month intervals, until all 5 Gaza districts are reached. The successful integration of mental health into primary health care has shown that it is possible to develop mental health services in low-resource and conflicted-affected settings.

summarizes how mental health services have been integrated into maternal and child health services in Pakistan.

\section{User and carer involvement}

Increasing participation of service users and carers is one of the major advances made in mental health care in the last decades. The recovery movement has validated the active engagement of

\section{Box 4 Case study: integration of mental health in maternal and child health services in Pakistan}

Mental health has been integrated into maternal and child health services in Pakistan using the Five-Pillars (5-PA) Approach to Maternal Psychosocial Well-Being. The approach is derived from the Thinking Healthy Programme: a cognitive-behaviour therapy-based psychosocial intervention for mothers with depression and their infants. The Thinking Healthy Programme is a targeted intervention for women suffering from perinatal depression and their infants. It was evaluated in a community-based setting in rural Rawalpindi by female community health workers, known in Pakistan as "lady health workers". There is good evidence for its effectiveness and it is aligned with the WHO Mental Health Gap Action Programme (mhGAP) intervention guidelines.

5-PA is an adaptation of the Thinking Healthy Programme in order to integrate it into a child nutrition and development programme. Thus, it is an example of delivery of mental health care to mothers and infants through a maternal and child health platform. The adaptation targets not only depressed women but also all mothers during pregnancy and in the 2 years after giving birth. The key feature of the approach is that it is integrated into and facilitates the delivery of a community-health-worker-delivered intervention for early child nutrition and development. Thus, whenever the community health worker delivers a session for child nutrition or development, she uses 5-PA to strengthen the key message and to provide the psychosocial intervention.

A pilot study has been successfully completed in one rural area and 120 community health workers have been trained. Evaluation of its impact is being tested through a cluster randomized controlled trial. Pilot results show that community health workers were able to apply the 5-PA effectively to their work, and the approach was found to be useful by them, their supervisors, the mothers and the families. 
people in accepting and overcoming the challenges of disability associated with mental health problems (20). Facilities should support service user involvement in decision-making at all levels, including the running of the facility as well as their personal treatment and care plans. Users might be also included in contributing to designing research studies as it is the case in a few countries such as the United Kingdom. Community mental health services should support families coping with the problems associated with chronic mental disorder in a family member, for example by developing programmes designed to decrease family burden and improve psychological support.

\section{Key recommendations for ministries of health}

The key recommendations summarized in Table 1 address 6 strategic interventions for service reorganization for ministries of health. Service reorganization cannot be carried out in isolation and it must be underpinned by policy and legislative reforms, complemented by promotion and preventive interventions, and informed by information, evidence and research. Furthermore the active involvement of users and carers should be promoted in the planning and review of delivery of care and reorganization of services.

\begin{tabular}{|c|c|c|}
\hline $\begin{array}{l}\text { Key recommendations for } \\
\text { strategic intervention }\end{array}$ & Essential actions for all countries & $\begin{array}{l}\text { Actions for consideration by countries } \\
\text { with more resources }\end{array}$ \\
\hline $\begin{array}{l}\text { 1. Integrate delivery of } \\
\text { interventions for priority } \\
\text { mental disorders, as identified } \\
\text { in the WHO Mental Health } \\
\text { Gap Action Programme } \\
\text { (mhGAP), in primary health } \\
\text { care and priority programmes. }\end{array}$ & $\begin{array}{l}\text { - Integrate care of priority disorders into the } \\
\text { basic package of services offered within } \\
\text { primary health care. } \\
\text { - Integrate care for common mental disorders } \\
\text { into the routine care for people affected by } \\
\text { noncommunicable diseases, maternal and } \\
\text { child health problems and HIV/AIDS. } \\
\text { Ensure availability of essential psychotropic } \\
\text { medications in primary health care settings. }\end{array}$ & \\
\hline $\begin{array}{l}\text { 2. Systematically strengthen the } \\
\text { capacity of non-specialized } \\
\text { health personnel for providing } \\
\text { evidence-based and quality } \\
\text { services for priority mental } \\
\text { disorders (identified in } \\
\text { mhGAP). }\end{array}$ & $\begin{array}{l}\text { Enhance the capacity of primary health care } \\
\text { workers at all levels to provide integrated } \\
\text { mental health care for priority mental } \\
\text { disorders, using the mhGAP intervention } \\
\text { guide and training materials. } \\
\text { Provide refresher training and supervision to } \\
\text { primary health care workers. }\end{array}$ & $\begin{array}{l}\text { - Include recognition and management } \\
\text { of common mental disorders } \\
\text { into training curricula of all health } \\
\text { personnel including integration into } \\
\text { family physician programmes. }\end{array}$ \\
\hline $\begin{array}{l}\text { 3. Scale up community-based } \\
\text { services, e.g. via community } \\
\text { outreach teams for defined } \\
\text { catchment areas, supported } \\
\text { residential facilities, supported } \\
\text { employment and family } \\
\text { support. }\end{array}$ & $\begin{array}{l}\text { Develop, via training/retraining and } \\
\text { supervision, multidisciplinary community } \\
\text { mental health teams to deliver integrated } \\
\text { community-oriented mental health care. } \\
\text { - Develop new cadres within the workforce } \\
\text { who are appropriate to the needs of the } \\
\text { reorganized mental health system (e.g. } \\
\text { project managers, case managers and } \\
\text { counsellors). } \\
\text { - Establish multidisciplinary outreach teams to } \\
\text { liaise with and support primary health care } \\
\text { services. }\end{array}$ & $\begin{array}{l}\text { - Provide psychological, } \\
\text { pharmacological and social } \\
\text { interventions for children and } \\
\text { adolescents with mental health } \\
\text { problems. } \\
\text { - Develop other community services, } \\
\text { e.g. daycare centres and community } \\
\text { residential facilities with different levels } \\
\text { of support provided by specialized and } \\
\text { nonspecialized teams. } \\
\text { Promote integration of mental health } \\
\text { interventions with income-generation } \\
\text { programmes and social services, e.g. } \\
\text { education and housing. }\end{array}$ \\
\hline $\begin{array}{l}\text { 4. Establish mental health } \\
\text { services in general hospitals } \\
\text { for outpatient and acute } \\
\text { inpatient care. }\end{array}$ & $\begin{array}{l}\text { - Develop outpatient care in general } \\
\text { hospitals staffed by core multidisciplinary } \\
\text { mental health teams catering to a defined } \\
\text { catchment area. } \\
\text { - Set up inpatient services for provision of } \\
\text { care within the defined catchment area of } \\
\text { people with acute exacerbations of mental } \\
\text { disorders. } \\
\text { - Ensure availability of essential psychotropic } \\
\text { medications in mental health units in } \\
\text { general hospitals. }\end{array}$ & $\begin{array}{l}\text { - Liaise and coordinate with existing } \\
\text { community mental health teams. } \\
\text { - Provide liaison psychiatric } \\
\text { interventions to other departments of } \\
\text { the hospital. }\end{array}$ \\
\hline
\end{tabular}




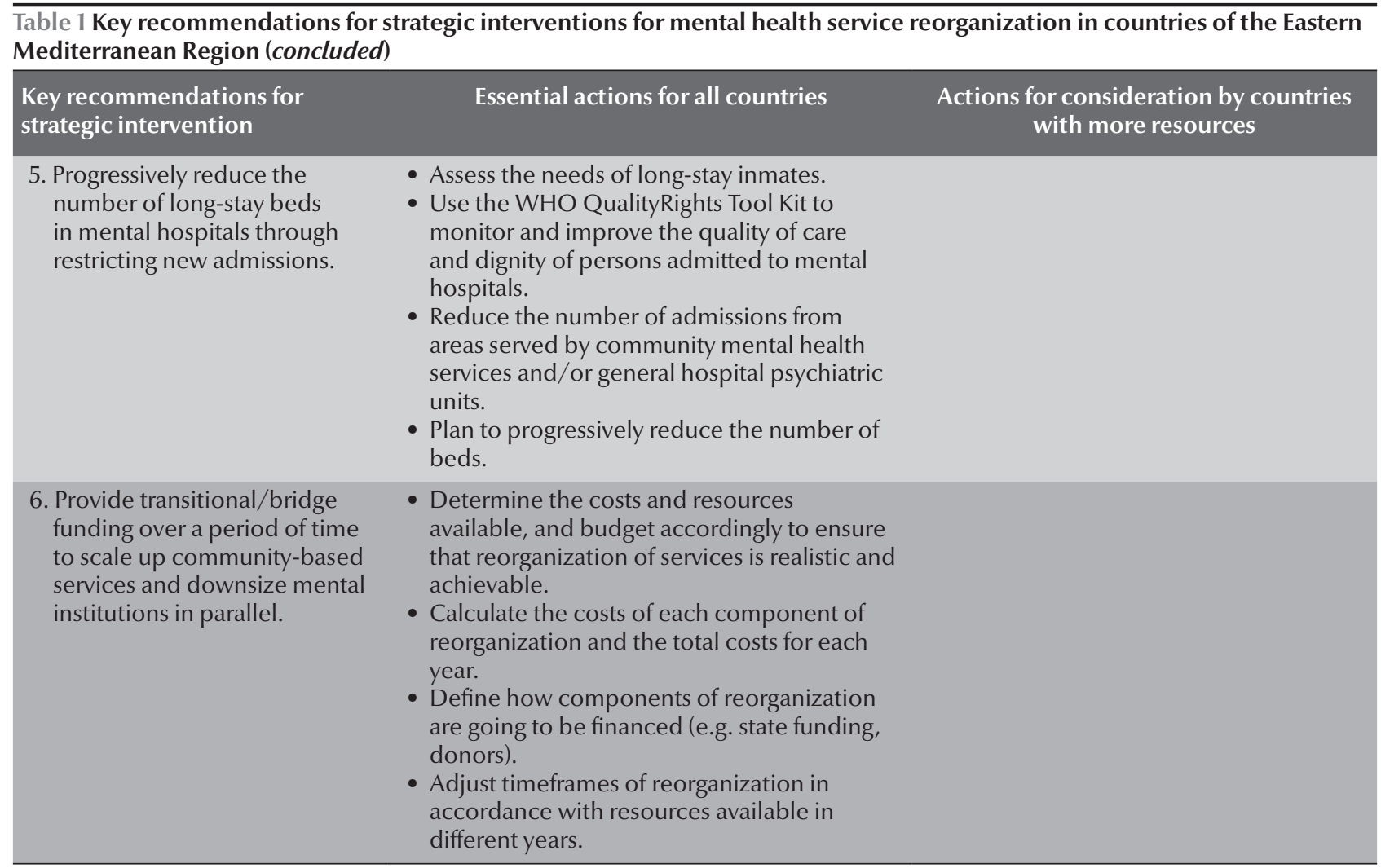

\section{References}

1. The world health report 2001. Mental health: new understanding, new hope. Geneva: World Health Organization; 2001.

2. Patel V, Araya R, Chatterjee S, Chisholm D, Cohen A, De Silva $\mathrm{M}$, et al. Treatment and prevention of mental disorders in low-income and middle-income countries. Lancet. 2007 Sep 15;370(9591):991-1005. PMID:17804058

3. Improving health systems and services for mental health. Geneva: World Health Organization; 2009.

4. Mental health atlas 2011: resources for mental health in the Eastern Mediterranean Region. Cairo: World Health Organization, Regional Office for the Eastern Mediterranean; 2013 (EMRO Technical Publication Series No. 41) (http://applications.emro.who.int/dsaf/emropub_2013_1578.pdf, accessed 5 February 2015).

5. Thornicroft G, Tansella M. The balanced care model for global mental health. Psychol Med. 2013 Apr;43(4):849-63. PMID:22785067

6. Araya R, Flynn T, Rojas G, Fritsch R, Simon G. Cost-effectiveness of a primary care treatment program for depression in lowincome women in Santiago, Chile. Am J Psychiatry. 2006 Aug;163(8):1379-87. PMID:16877650

7. Patel V, Weiss HA, Chowdhary N, Naik S, Pednekar S, Chatterjee $\mathrm{S}$, et al. Effectiveness of an intervention led by lay health counsellors for depressive and anxiety disorders in primary care in Goa, India (MANAS): a cluster randomised controlled trial. Lancet. 2010 Dec 18;376(9758):2086-95 PMID:21159375

8. Patel V, Weiss HA, Chowdhary N, Naik S, Pednekar S, Chatterjee $\mathrm{S}$, et al. Lay health worker led intervention for depressive and anxiety disorders in India: impact on clinical and disability outcomes over 12 months. Br J Psychiatry. 2011 Dec;199(6):459-66. PMID:22130747
9. Patel V, Saxena S, editors. Transforming lives, enhancing communities: innovations in mental health. WISH Mental Health Report 2013. Doha: World Innovation Summit Group for Health; 2013 (http://www.wish-qatar.org/app/media/381, accessed 5 February 2015).

10. Van Wijngaarden B, Schene A, Koeter M, Becker T, Knapp M, Knudsen HC, et al.; EPSILON Study Group. People with schizophrenia in five countries: conceptual similarities and intercultural differences in family caregiving. Schizophr Bull. 2003;29(3):573-86. PMID:14609250

11. Tansella M. Community psychiatry without mental hospitals-the Italian experience: a review. J R Soc Med. 1986 Nov;79(11):664-9. PMID:3795212

12. Thornicroft G, Bebbington P. Deinstitutionalisation-from hospital closure to service development. Br J Psychiatry. 1989 Dec;155:739-53. PMID:2695205

13. Caldas de Almeida JM, Killaspy H. Long-term mental health care for people with severe mental disorders. Brussels: European Union; 2011.

14. Innovation in deinstitutionalization: a WHO expert survey. Geneva: World Health Organization; 2014 (http://apps.who. int/iris/bitstream/10665/112829/1/9789241506816_eng.pdf, accessed 5 February 2015).

15. WHO QualityRights tool kit. Assessing and improving quality and human rights in mental health and social care facilities. Geneva: World Health Organization; 2012 (http://apps.who. int/iris/bitstream/10665/70927/3/9789241548410_eng.pdf, accessed 5 February 2015).

16. Kaaya S, Eustache E, Lapidos-Salaiz I, Musisi S, Psaros C, Wissow L. Grand challenges: Improving HIV treatment outcomes by integrating interventions for co-morbid mental illness. PLoS Med. 2013;10(5):e1001447. PMID:23700389 
17. Ngo VK et al. Grand challenges: integrating mental health care into the non-communicable disease agenda. PLoS Med 2013;10(5):e1001443. PMID:23690753

18. Integrating the response to mental disorders and other chronic diseases in health care systems. Geneva: World Health Organization; 2014 (http://apps.who.int/iris/bitstre am/10665/112830/1/9789241506793_eng.pdf, accessed 5 February 2015).

19. Patel V, Belkin GS, Chockalingam A, Cooper J, Saxena S, Unützer J. Grand challenges: integrating mental health services into pri- ority health care platforms. PLoS Med. 2013;10(5):e1001448. PMID:23737736

20. Rahman A, Surkan PJ, Cayetano CE, Rwagatare P, Dickson KE. Grand challenges: integrating maternal mental health into maternal and child health programmes. PLoS Med. 2013;10(5):e1001442. PMID:23667345

21. Deegan PE. Recovery: the lived experience of rehabilitation. Psychosoc Rehabil J. 1988;11(4):11-9.

\section{Continued from page 397}

${ }^{3}$ Department of Psychological Sciences, University of Liverpool; Child Mental Health Unit, Royal Liverpool Children's Hospital, Liverpool, United Kingdom. ${ }^{4}$ Mental Health and Substance Abuse Department, World Health Organization Regional Office for the Eastern Mediterranean, Cairo, Egypt. ${ }^{5} \mathrm{CBM}$ International, West Africa Regional Office, Lomé, Togo. ${ }^{6}$ World Federation for Mental Health, London, United Kingdom. ${ }^{7}$ World Organization of Family Doctors, Sydney; Faculty of Medicine, Nursing and Health Sciences, Flinders University, Adelaide, Australia. ${ }^{8}$ Department of Psychological Sciences, University of Liverpool, Liverpool, United Kingdom. ${ }^{9}$ Research Action on Mental and Brain Disorders; ${ }^{10}$ Mental Health and Substance Abuse Department, World Health Organization Headquarters, Geneva, Switzerland. "Basic Needs, Leamington Spa, United Kingdom. 